\title{
Nuevos peregrinos y nuevos turistas para la sostenibilidad medio-ambiental: el turismo lento como vía para la conservación de la autenticidad del patrimonio tangible e intangible de un territorio
}

\author{
Filippo Pistocchi ${ }^{\star}$, Roberta Curiazi ${ }^{* \star}$ y Fiorella Dallaria ${ }^{\star \star \star}$
}

\section{RESUMEN}

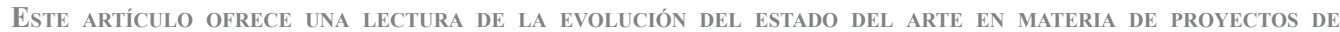
DESARROLlo TURíSTICO LOCAL SOSTENIBLE, EN EL MARCO DEL TURISMO “LENTO" DE PEREGRINACIÓN, COMO APLICACIÓN CONCRETa de POLÍTICAS de ARMONIZACIÓN ENTRE TURISMO Y AMBIENTE. SE HARÁ REFERENCIA, COMO marco empírico, a unos casos en el ámbito interregional (La Vía Francigena y el Parque Nacional de las Florestas Casentinesi), dentro de un ámbito regional más amplio (Europa). Las experiencias mencionadas, QUE SE ILUSTRARÁN SEGÚN UN MARCO PREVALENTEMENTE CUALITATIVO Y DESCRIPTIVO, TANTO INTERDISCIPLINARIO COMO INTERCULTURAL, HAN UTILIZADO PROTOCOLOS DE SOSTENIBILIDAD DICTADOS POR ORGANIZACIONES INTERNACIONALES Y EUROPEAS, LO QUE RESULTA EN LA APLICACIÓN EFECTIVA DEL TURISMO LENTO DE "PEREGRINACIÓN"; Y EN SU APOYO COMO PRÁCTICA TURÍSTICA ECOLÓGICAMENTE SOSTENIBLE EN RELACIÓN CON EL MÁS AMPLIO MOVIMIENTO CULTURAL DEL "REVERDECIMIENTO DE LA RELIGIÓN".

Palabras Clave: nuevos peregrinos - sostenibilidad medio ambiental - itinerarios culturales - Europa.

New Pilgrims and New Tourists for Environmental Sustainability: Slow Tourism as a Way to Conserve the Authenticity of a Territory's Tangible and Intangible Heritage

Abstract

This ARTICLE OFFERS A READING OF THE EVOLUTION OF PLASTIC ARTS IN LOCAL SUSTAINABLE DEVELOPMENT TOURISM PROJECTS IN THE FRAME OF "SLOW" TOURISM PILGRIMAGES AS A CONCRETE APPLICATION OF POLICIES OF HARMONIZATION BETWEEN TOURISM AND THE ENVIRONMENT. IN AN EMPIRICAL FRAMEWORK, WE WILL REFER TO SOME INTERREGIONAL cases (La Vía Francigena y el Parque Nacional de las Florestas Casentinesi) within a larger regional SCOPE (EUROPE). THE EXPERIENCES MENTIONED, DESCRIBED WITHIN A PREDOMINANTLY QUANTITATIVE AND QUALITATIVE INTERDISCIPLINARY AND INTERCULTURAL FRAMEWORK, HAVE USED PROTOCOLS OF SUSTAINABILITY DICTATED BY INTERNATIONAL AND EURPEAN ORGANIZATIONS, RESULTING IN THE EFFECTIVE APPLICATION OF THE SLOW-TOURISM OF PILGRIMAGES, AND IN ITS SUPPORT OF SUSTAINABLE ECOLOGICAL TOURISTIC PRACTICE WITHIN THE LARGER CULTURAL MOVEMENT OF "THE GREENING OF RELIGION".

KEYWORDS: NEW PILGRIMS - ENVIRONMENTAL SUSTAINABILITY - CULTURAL ITINERARIES - EUROPE.

\footnotetext{
* Sede de Geografía y Escuela de Idiomas y Letras, Traducción e Interpretación, Universidad de Bologna. Correo electrónico: filippo.pistocchi@unibo.it.

** Departamento de Desarrollo, Ambiente y Territorio, FLACSO Ecuador. Correo electrónico: rcuriazi@flacso.edu.ec.

*** Departamento de Ciencias para la Calidad de la Vida (sede di Rimini), Universidad de Bologna. Correo electrónico: fiorella.dallari@unibo.it.
} 


\section{Introducción}

$\mathrm{D}$ esde hace algún decenio el turismo ha tomado dinámicas, formas y dimensiones seguramente importantes y significativas: si por un lado ha abierto el camino a nuevas rutas y acercado entre ellas las distancias entre "periferias" y "centros", por otro lado de alguna manera ha afectado a territorios enteros, en particular sus ecosistemas y tipicidades culturales locales, sobre todo en los ámbitos rurales, más vulnerables. Eso sucede porque este "movimiento particular de personas", dirigido a la experimentación de algo nuevo o diferente, si por un lado permite generar servicios, flujos importantes de dinero y también formas de inversión en los territorios involucrados, por el otro lleva al consumo excesivo de un cierto recurso territorial o al "aplanamiento" cultural (Vandergeest, 1988).

En el escenario contemporáneo, especialmente europeo, muchas preguntas surgen en torno a la relación entre el medio ambiente y la sostenibilidad de las peregrinaciones, como importante fenómeno turístico en expansión. La cuestión de si este fenómeno es realmente sostenible requiere una respuesta necesaria frente a su proliferación, en un contexto turístico general en que está creciendo el impacto del overtourism en la dimensión local. Esto supone una referencia estratégica particular para la gobernanza ambiental (Erkuş-Öztürk y Eraydın, 2010) y, en cualquier caso, para un desarrollo local sostenible y sustentable del territorio.

El redescubrimiento de la peregrinación ha tenido un impacto emocional que ha llevado a la imitación de las modalidades de la experiencia religiosa, donde la dimensión humana parece reanudar su tiempo manifestando nuevas formas de expresión de turismo religioso: han nacido así el slow tourism (Fullagar et al., 2012); el movimiento lento, (Calzati y De Salvo, 2012) con peregrinos informales con respecto a los peregrinos medievales (Baudone, 2014); un número creciente de viajeros posmodernos que optan por no utilizar la movilidad del transporte moderno (Collings-Kreiner, 2014); y otros que viven esta experiencia de una manera cada vez más virtual, gracias al creciente apoyo de las ICT (de Ascanii y Cantoni, 2016) y en un complejo mix entre las dos tipologías de experiencias (Azzari \& Dallari, 2018), fast and slow.

¿Cuán la salvaguardia ecológica resulta presente en una visión pro-activa de la actividad turística, como es el turismo de peregrinación? Esta relación parece obvia, pero no es trivial: un peregrino tradicional, que hace un recorrido por áreas naturales para llegar a un lugar sagrado, considera la naturaleza como parte de la Creación, un elemento que lo conduce a formas contemplativas útiles para elevar su alma; como sucedió en el siglo XVIII, cuando los grandes viajeros europeos trataron de elevar sus mentes y almas viajando a través de la Europa del Grand Tour. De la misma manera, un hicker, un trekker, un biker o un turista genérico, que recorre caminos y rutas fuera de las grandes ciudades, quiere más que nunca que la naturaleza se quede intacta. En todos estos casos, que se hable de un turista "religioso", "deportivo", "ambiental" o "cultural", su "ocupar, cruzar y usar" el territorio nunca será dañino para el medio ambiente, ya que la naturaleza y el paisaje no son un espacio trivial para los que "caminan", sino dimensiones protagónicas de toda la experiencia turística que se realiza y vive.

El turismo sostenible, que ha sido ampliamente descrito tanto en términos teóricos como aplicativos, expresa probablemente la síntesis más fascinante del estudio geográfico de los territorio, ya que con eso se intenta garantizar un equilibrio dinámico, positivo, adaptativo (resiliencia) en los aspectos económicos (crecimiento, que solo no puede garantizar el bienestar), en los sociales (inclusión, participación) y en los ambientales (protección, tutela, reducción del riesgo. "Hacer turismo" significa intervenir masivamente en todos estos aspectos, que constituyen la estructura del territorio y construyen su identidad. Se vuelve entonces muy importante hoy en día, en una época de cambios grandes (climáticos, geopolíticos, geoeconómicos), guiar todos los territorios, también los más pequeños, hacia una conciencia más profunda y "ética" 
del desarrollo. Hacerlo a través de formas de turismo "atento", y por eso "lento", parece ser una solución adecuada. No es entonces casual que, con respecto al caso italiano, el número de parques nacionales haya aumentado justo entre finales de los años ochenta e inicio de los noventa ${ }^{1}$, en respuesta a la aplicación de las políticas globales y locales para la salvaguardia del medio-ambiente insertadas en los programas internacionales regionales y locales de desarrollo sostenible. Asimismo, el turismo ambiental tuvo una empinada en sus manifestaciones más amplias: difundidas, agroturismo, itinerarios culturales.

El artículo quiere ser en definitiva una narración divulgativa, y un momento de reflexión, sobre el papel de los peregrinos dentro del ámbito turístico. Se intentará proporcionar la posibilidad de combinar conceptual y prácticamente las experiencias de peregrinaciones - las tradicionales (que se mueven por la fe o la búsqueda personal de una dimensión más espiritual) y las "nuevas" (itinerarios religiosos recorridos por razones distintas de la mera sacralidad de la experiencia) - con la protección y conservación del medioambiente, gracias a políticas de salvaguardia ambiental dirigidas a promover formas de turismo "lento" y más "responsable", que están caracterizando la experiencia europea como expresión de formas espontáneas de turismo sostenible, ejemplos de una perfecta integración de la actividad con el medio ambiente en su dimensión más compleja.

\section{Peregrinaciones contemporáneas frente al cambio global y a las acciones político- sostenibles: el estado del arte}

Los peregrinos-turistas contemporáneos se demuestran cada vez más fascinados por las experiencias de "caminar", tanto como los peregrinos convencionales; por esta razón se convierten hoy en día en nuevos íconos del turismo cultural (religioso y ambiental) (LoisGonzález, Santos Solla, 2014). Su experiencia es, obvia y notablemente, diferente de las "vacaciones ordinarias", con especial referencia al turismo de playa y sus manifestaciones de masas, por al menos dos razones: los peregrinos buscan un acercamiento sostenible con el medio ambiente, que es parte integrante de su experiencia turística. Por esta razón se considera al sacred gaze como un fenómeno floreciente en comparación con cualquier otro leisure gaze (Dallari, 2016).

Con el tiempo, el turismo religioso y las peregrinaciones han experimentado muchos cambios, tanto por razones espirituales como culturales, y también por acontecimientos históricos, cambios geopolíticos y desafíos geoeconómicos (guerras, conflictos sociales, acuerdos políticos, plagas, etc.). Es cierto que, en el pasado, las percepciones y creencias de los peregrinos eran mucho más fuertes, más dogmáticas y absolutas con respecto a la espiritualidad del viaje y la herencia espiritual que anima a los turistas "comunes" y de masas en la actualidad (Tinacci, 2015): éstos suelen estar menos involucrados e incluidos en su experiencia, a menos que no se trate de "tourist walkers" (Badone, 2014). En cualquier caso, estas formas de oferta, basadas en la estrecha relación entre naturaleza y acciones humanas, entre funciones biológicas (Pungetti, 2012) y percepción cultural de tiempo y espacio, pueden jugar un papel importante para un desarrollo local sostenible dentro de un territorio "equilibrado" (Trono et al., 2017; Corinto, 2017). De hecho, esta relación no conduce precisamente a la transformación y adaptación de un territorio a la demanda turística, sino a la protección y valorización del mismo a través de un comportamiento sostenible (típico de la sostenibilidad y de una visión más atenta al futuro).

El resultado es un elemento geográfico, el paisaje religioso, compuesto por el patrimonio religioso (Nannini, 2017) tangible e intangible, que es importante tanto para la preservación de las tradiciones como para la promoción y el desarrollo continuo del territorio (Dallari y Mariotti, 2006; Dallari, 2016; Dallari y Mariotti, 2017; Senesi, 2017; Azzari y Dallari, 2018). De aquí

1 De los 22 parques existentes en la actualidad, 17 de esos se instituyeron en ese período. 
muchos trabajos científicos se han desarrollado a nivel europeo² (Mitchell, 1994; Minkenberg, 2002; Cresswell, 2003; Collins-Kreiner, 2010), monitoreando la evolución del sector en respuesta a exigencias crecientes de valorización sostenible de territorios a fuerte vocación turística, cultural y ambiental al mismo tiempo.

El cambio cultural que se dio a nivel global, que ocurrió hace varias décadas y llevó la atención hacia la comprensión y el redescubrimiento de las raíces identitarias de los territorios, representa realmente un elemento de impulso para el desarrollo local tanto como la promoción de experiencias culturales y personales, y contribuye a dibujar lo que se conoce como estilo de vida "postmoderno" de leisure. Los peregrinos y turistas posmodernos están interesados en actividades culturales y experienciales auténticas: caminar despacio, andar en bicicleta, viajar por senderos e itinerarios o visitar sitios particulares por algunas razones específicas, como medio para restaurar el cuerpo y el alma, encontrarse a sí mismos o encontrarse con los demás (Dallari, 2016; Almatourism, 2017). Las rutas religiosas del pasado pueden entonces convertirse hoy en día en recursos turísticos más completos y mejor estructurados, ya que condensan una amplia gama de tipologías de motivaciones turísticas y formas de turismo: cultura, patrimonio, arte, moda, paisajes, áreas rurales y naturaleza, actividades físicas y deportivas, conocimiento e interacción social con los residentes, además del propósito religioso (Dann, 1981; Dallari, 2012; Ray, 2012; Collins-Kreiner, 2017).

En su estilo de vida, los peregrinos formales e informales respetan el medio ambiente de una forma espontánea y sostenible, incluso en un escenario geopolítico transformado, que ha proporcionado las condiciones para un crecimiento en números, especialmente en las principales peregrinaciones europeas (Roma, Jerusalén y Santiago de Compostela): del Atlántico, finis terrae (Gonzaléz-Paz, 2015), a los Urales, y el finis terrae de Santa Maria di Leuca en el Salento italiano, que fue la puerta de entrada a la Tierra Santa y a Jerusalén, y fue la última escala de peregrinaciones procedentes del Norte de Europa (Cavaliere, 2015). Lo mismo sucede en el resto del mundo; por nombrar algunas: Hajj islámico, peregrinación obligatoria a La Meca, peregrinación budista de Shikoku (Japón), peregrinación hindú Kumbh Mela (India), peregrinación a las Cuatro Montañas Sagradas del Budismo y las Cuatro Montañas Sagradas del Taoísmo (China), peregrinación a Mariana de Guadalupe (México).

El redescubrimiento del patrimonio presente en los territorios pone de relieve la movilidad espiritual y cultural vinculada al cambio cultural dentro del proceso de construcción del patrimonio contemporáneo. Las rutas de peregrinación y los lugares sagrados están ahora incluidos en la Lista del Patrimonio de la UNESCO tangible e intangible. Estos sitios fueron reconocidos oficialmente también por el Consejo de Europa y por organismos nacionales, regionales y locales. Estamos ahora experimentando una des-diferenciación creciente y real en la que llamamos una "nueva sensibilidad religiosa" (Collings-Kreiner, 2014, 2010). Es 1982 (Año Santo de Compostela), el año que da testimonio de un inesperado y repentino auge de peregrinos y viajeros ${ }^{3}$. Unos años más tarde, tanto el Gobierno español (1985) como el Consejo de Europa (1987) revelaron su interés en ese itinerario: los miembros europeos le otorgaron a Santiago de Compostela el título de Itinerario Cultural Europeo.

A pesar de ser un segmento de nicho en comparación con el turismo de masas (y en particular el turismo marítimo), esta experiencia cultural y emocional está en constante crecimiento (3.000 peregrinos en 1990; 60.000 en 1993; 128.000 en 1999 según Brukner (2001); 215.000 en 2013, según la Alianza de Religiones y Conservación - ARC [2014]) y está recibiendo el apoyo de

2 Se recuerda entre ellos el archivo de Almatourism, revista de la Università di Bologna, que desde años dedica muchas investigaciones a este tema. Entre las publicaciones más recientes: Vol. 9, N. 8 (2018), Sacred Landscape: An Invaluable Resource between Knowledge and Sustainable Local Tourism Development; Vol. 8, N. 16 (2017), Romei and Francigeni. The Sources for an European Pilgrimage History; Vol. 8, N.6 (2017), The Via Francigena: the Long Way of Peace among the European Landscapes.

3 El mismo Papa Juan Pablo II visitó Santiago de Compostela como peregrino durante su viaje apostólico a España; en esa ocasión pronunció el discurso titulado "Acta Europeista en Santiago de Compostela" (Vaticano, 1982), que todavía se considera como la más profunda contribución religiosa y geopolítica a este contexto. 
organismos internacionales, tanto como de la Organización Mundial del Turismo de las Naciones Unidas (UNWTO) y el Consejo de Europa. Este último, al reconocer y aceptar el "Camino de Santiago" como primera peregrinación europea (1987), puso en marcha el Programa de Rutas Culturales Interpretando el Patrimonio Europeo y, desde 1996, ha confirmado la idea de una perspectiva renovada de la relación entre patrimonio y sociedad, donde el concepto sagrado tradicional está cada vez más conectado a los niveles más altos de sostenibilidad (Dallari, 2016). Además, desde el 1987 hasta el 2016, el Consejo Europeo ha reconocido 32 rutas: las más importantes y vivas de ellas, y no completamente sostenibles ${ }^{4}$, son cuatro antiguas peregrinaciones: Rutas de Peregrinación de Santiago de Compostela (1987), Via Francigena de Sigeric (1994), Caminos de San Miguel (2007) y Ruta de Saint Olaf Ways (2010), así como otras rutas temáticas religiosas como la Ruta de San Martín de Tours (2005) y la Ruta Europea de las Abadías Cistercienses (2010). Varios de estos itinerarios son paisajes históricos, otros son paisajes culturales, donde un paisaje cultural y ambiental, como ya afirmado, resulta de una mezcla de patrimonio material e inmaterial, en que la naturaleza es un elemento básico para la ruta en sí.

Actualmente, al expediente que se presentará al Consejo de Europa para su aprobación oficial se están agregando más rutas hacia Roma, con la ciudad destino final del peregrino; entre ellas, la Vía Romea de Albert von Stade y la Via Francigena del Sur.

Sigeric, una Romea Francigena en strictu sensu, es una de las principales rutas que conectan el Norte de Europa con Roma y que finalmente conduce a Jerusalén. Esa constituye una parte esencial de todo el proyecto europeo: partiendo de Canterbury, conecta la tierra de los Francos con Roma; de ahí, el nombre del camino.

Dentro de este contexto es importante mencionar también el caso de otras rutas de peregrinación antiguas, traídas a vida nueva por actores públicos, como la Caminata de San Francisco (Dallari, 2012), donde dos itinerarios a pie se superponen para llegar a más destinos religiosos (Rieti, Roma y Asís) ${ }^{5}$.

\section{Peregrinaciones, itinerarios y paisajes rurales: la evidencia empírica entre espiritualidad y sostenibilidad}

La peregrinación es una fuerza motriz poderosa para el desarrollo de las áreas rurales y los territorios más pequeños, y especialmente para aquellas áreas en condiciones marginales, porque puede generar beneficios sociales y económicos. Sin embargo, los efectos negativos del turismo son más evidentes que las buenas prácticas, donde la falta de una planificación adecuada afecta a menudo al delicado equilibrio y a las dinámicas socio-ambientales de estos territorios. El resultado es un medio ambiente consumido.

Como lo afirma Tsunekiyo Tanaka (2014), presidente de Jinja Honcho, la Asociación de Santuarios Shinto ${ }^{6}$ : "tener respeto reverencial a la naturaleza, apreciar las bendiciones de la naturaleza y vivir juntos con la naturaleza son principios que nos gustaría compartir con nuestros peregrinos y peregrinas de todo el mundo". Por otro lado Park (1994: 3) afirma que "la religión prohíbe ciertas actividades, restringe a otras y alienta a otras más". Por lo tanto, la religión, las peregrinaciones religiosas, pero también las rutas culturales basadas en itinerarios religiosos antiguos, son tres elementos fundamentales para la protección ambiental, porque suelen ser más conservadoras que otras formas de prácticas humanas y el turismo en general: el medio ambiente y el paisaje son necesarios no sólo por razones estéticas, sino también porque su belleza y su

4 El medio ambiente, de hecho, ha sido transformado y adaptado por las comunidades locales para mejorar su calidad de vida y su internacionalización; de aquí la parcial sostenibilidad de estos itinerarios.

5 Las rutas incluyen varias escalas: el primer itinerario, la Romea, como lo indica Dante Alighieri en su obra Vita Nova, es la antigua peregrinación asociada con el culto de San Francisco, el santo que celebró la naturaleza como una expresión divina; un comportamiento presente en todas las religiones.

6 Reunión anual de la Red Verde de Peregrinación (1 - 5 de junio de 2014). 


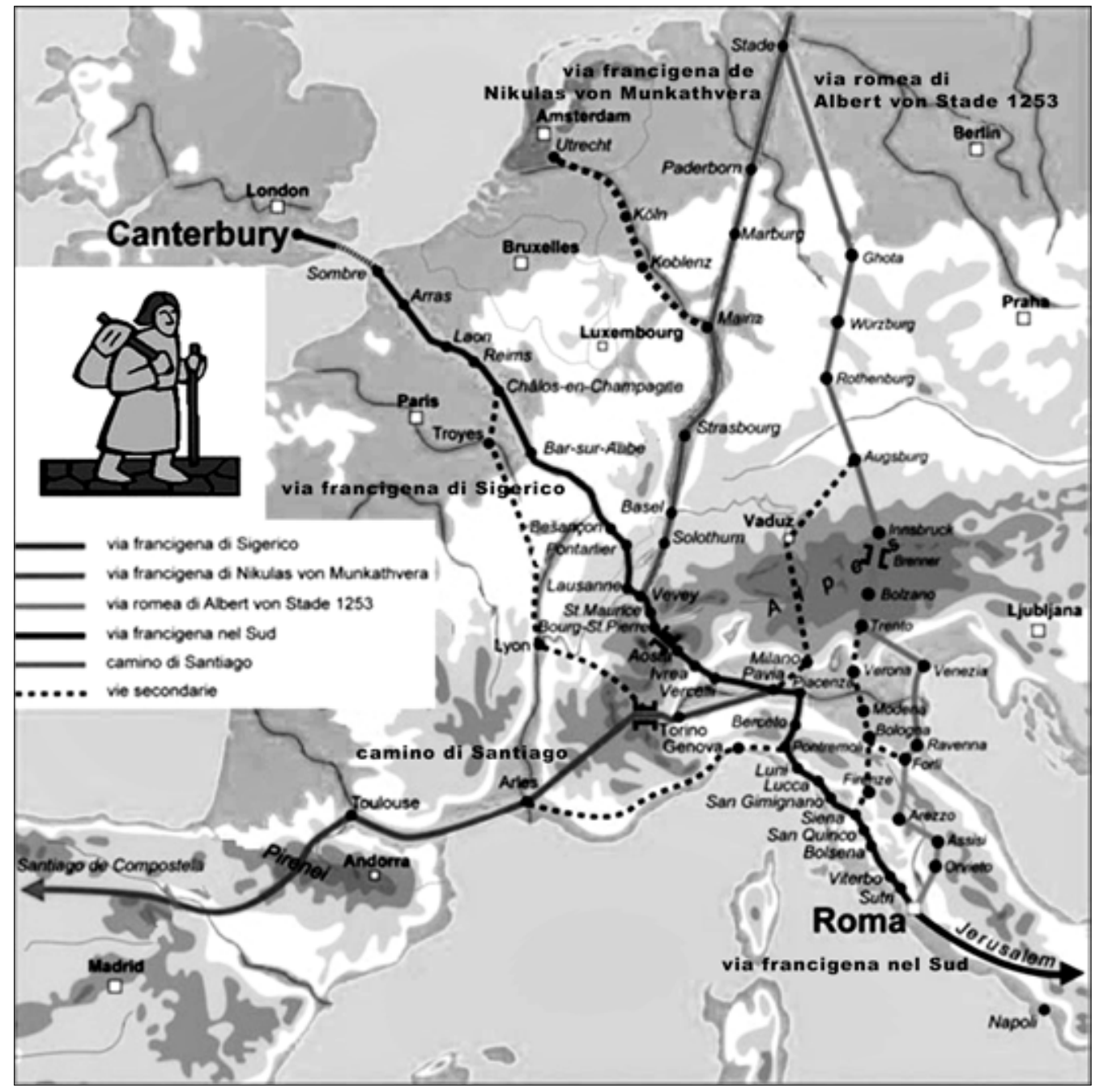

MAPA 1. Vías de los antiguos Peregrinos en Europa.

FUENTE: HTTP://WWW.CIOCCOLETA.IT/ROMEA-GERMANICA-AND-FRANCIGENA-TWO-ANCIENT-PILGRIMS-WAYS/ 
sentido de paz tienen un profundo significado ontológico, que es parte de la experiencia turística en sí. En otras palabras, la naturaleza para un viajero religioso es parte de la Creación; para un turista cultural y para un eco-turista es importante y significativa sólo si es conservada. Se deduce entonces que el ambiente es "factor de oferta" fundamental para este tipo específico de experiencia.

En el intento de permitir que las comunidades y sociedades locales se beneficien de los flujos de turismo espiritual en términos económicos, sociales y sostenibles, la OMT y los otros organismos internacionales y nacionales del sector se comprometen a explorar nuevas formas para integrar la "cultura viva", las tradiciones y las creencias en el turismo y, al mismo tiempo, respetando los cuatro pilares de la sostenibilidad: medio ambiente, economía, sociedad y cultura. Según Eugenio Yunis (2009: 21), ex Director de la Sección de Desarrollo Sostenible del Turismo de la OMT,

“...esto sucede en primer lugar a través de lo que podríamos llamar turismo religioso, que incluye peregrinajes y visitas a lugares sagrados para devoción, espiritualidad y culto; y, en segundo lugar, a través de formas de turismo que tienen lugar en edificios o sitios religiosos, que normalmente se pueden considerar como parte de un segmento más amplio, denominado generalmente turismo cultural. El término peregrinación designa un largo viaje con un gran significado moral o espiritual; pero, en términos de turismo, peregrinación significa un gran volumen de personas que provienen de diferentes regiones o países para reunirse en el mismo lugar, a menudo en un momento específico".

El paisaje religioso, formado por elementos evocadores y que crea nuevos patrones territoriales (Niglio, 2018; Yoshihara e Inoue, 2018; De Waal, 2018), está profundamente relacionado con las peregrinaciones y las actividades religiosas. El paisaje que rodea y completa el espacio de una peregrinación es significativo y notable por sus elementos, porque el peregrino, el caminante y el turista buscan un ambiente que le dé un profundo significado no sólo a su experiencia temporal, sino a su vida también. Por estas razones la autenticidad de lugares y personas (por los que viven en ese lugar y los que lo experimentan) debe ser prominente en cualquier plan maestro para la promoción del turismo y el desarrollo territorial local. El paisaje se convierte en una epifanía geográfica compleja y, preferiblemente, debería ser un entorno socialmente sostenible, basado en las relaciones entre el alma, la vida y la naturaleza (Pungetti, 2018), y el patrimonio social tangible e intangible en sus diversas interpretaciones geográficas (Cosgrove, 1984), generado conjuntamente por actores humanos y elementos naturales.

Esta nueva concepción del paisaje juega un papel fundamental en la explicación de los patrones posmodernos de peregrino/viajero: caminar, mirar, rezar, fotografiar y recordar una experiencia son partes integradas de la vida cotidiana de alguien.

El escenario actual entonces ha experimentado nuevas formas emergentes de turismo, que podemos definir como "inteligentes" y "sostenibles". Sin embargo, el tema de la conservación de la naturaleza y del patrimonio no es nuevo: las sociedades modernas están acostumbradas a proteger el medio ambiente con parques naturales y áreas naturales protegidas; las civilizaciones antiguas expresaban su religión y el vínculo con él "más allá", mediante ritos y acciones que tenían lugar no sólo en los templos o en edificios sagrados en las áreas urbanas, sino también en los espacios rurales; los bosques sagrados y los montes sagrados eran lugares de destino importantes para los "peregrinos" (Timothy, 2003). Se trata de un nuevo estilo de vida sostenible, originado desde la transición socio-ecológica: una necesidad insuperable para las nuevas generaciones, como expresión de una re-convergencia de experiencias espirituales y físicas, ya que en esta era global la modernización, la urbanización, la industrialización y el turismo tienen una gran influencia en los grupos humanos y la cultura, y tienden a transformar la naturaleza y el medio ambiente. 
En el caso de los senderos de los peregrinos, a menudo esos pasan a través de largas áreas no urbanizadas, periféricas y rurales, que hoy se enfrentan con un problema estructural: el abandono de la tierra, un complejo proceso multidimensional con aspectos económicos, ambientales y sociales interrelacionados. Como resultado, con la despoblación del campo, una sociedad rural envejecida, y un mercado de trabajo cada vez más competitivo, se eliminan cada vez más tierras agrícolas de baja productividad. Este fenómeno es muy común en Europa: las áreas marginales se han visto particularmente afectadas, desde los Alpes hasta los Pirineos, desde el Báltico hasta los Cárpatos y los Balcanes, en Portugal, en el centro de España, en Sardegna (Italia), en la antigua Alemania Oriental, en Polonia, en el Norte de Suecia y el Norte de Finlandia (Rewilding Europe, 2016).

Una solución obvia podría ser la aplicación de la Política Agrícola Común (PAC) de la UE, que ha desempeñado un papel importante en la configuración del paisaje agrícola en Europa. Una acción más compleja y bien estructurada sería, en cambio, la implementación de actividades agrícolas y rurales, y turísticas, hacia un turismo religioso en particular. Significaría trabajar con los terratenientes y las comunidades locales, si bien algunas comunidades rurales locales ya hayan comenzado a interactuar con los viajeros, e incluso con un enfoque de desarrollo sostenible local. Esto puede significar incluir también el turismo eno-gastronómico ligado al consumo y la comercialización del vino y de la comida típica, como sucede en el ámbito del Parque Nacional de las Florestas Casentinesi (Región Emilia-Romagna, Italia), que aplica claramente este tipo de política de valoración de los recursos locales, pero también juntando este tipo de oferta a viejas prácticas rurales y actividades de ecoturismo.

\section{Una perspectiva geográfica en torno a los indicadores de sostenibilidad vinculados a las nuevas peregrinaciones}

En las últimas décadas la Geografía ha asumido una visión holística y un enfoque sistémico al analizar todas las dinámicas territoriales (Von Bertalanffy, 1972), y esto también en el ámbito turístico. Según esta visión, el paisaje es un campo desafiante y multinivel (Dallari y Niglio, 2018), que implica la conexión entre geografía cultural y governance local, con sus políticas para el desarrollo territorial sostenible, incluida la protección del medio ambiente. Por lo tanto, el medio ambiente está en el centro, convirtiéndose en el corazón de la creatividad humana, mientras que los lugares y los paisajes deben analizarse como el resultado visible de la dimensión del patrimonio y la cultura locales.

En consecuencia, si hablamos de una "cultura de las peregrinaciones", también debemos reflexionar sobre la sostenibilidad socio-ecológica, es decir, sobre el equilibrio del ecosistema, la eficiencia económica, la equidad y la cultura intra e intergeneracional. Esta perspectiva fue aprobada en 1992 por la CNUMAD y la UNESCO, y se ajusta periódicamente junto con documentos y planes para la naturaleza y la protección del paisaje, como por ejemplo el programa Man and Biosphere (UNESCO, 1971), la Convención de Paisajes Culturales (UNESCO, 1992) y el Convenio Europeo del Paisaje (Consejo de Europa, 2000), destinado a promover la protección, la gestión y la planificación de los paisajes europeos y establecer la cooperación territorial e institucional para los problemas del paisaje a escala europea. Desde el 2003, el patrimonio religioso y los sitios sagrados han recibido especial atención también por ICCROM (2003), ICOMOS (2005; 2011) y Iucn/Mab's UNESCO (2012).

En los últimos años ha surgido la cuestión de una estrategia integrada con referencia a todo el patrimonio cultural, que propone una guía para una gestión sostenible de los bienes religiosos, con la participación de las autoridades civiles y religiosas en todos los niveles (Young, 2016); donde el término sitio sagrado abarca áreas de especial significado espiritual para las personas y las comunidades, y el término sitio natural sagrado corresponde a áreas naturales que tienen un significado espiritual especial (UICN / UNESCO, 2008). Dentro de las 16 categorías de interés religioso de la UNESCO, se considera que 5 grupos requieran una gestión sostenible: sitios 
arqueológicos y urbanos, paisajes, monumentos / estructuras y rutas (itinerarios culturales - rutas de peregrinación -, incluidas las estructuras religiosas). Según WHC (UNESCO PRI-SM, 2010), el patrimonio religioso difiere de otras formas de patrimonio. En particular, las áreas religiosas son los lugares protegidos más antiguos del planeta y son de "vital importancia para salvaguardar la diversidad cultural y biológica, para las generaciones presentes y futuras”: ¿podrían entonces considerarse una "forma antigua" de sostenibilidad?

Turistas y peregrinos, que visitan un sitio sagrado o caminan por una ruta sagrada que finalmente conduce a un edificio religioso, prestan atención al entorno natural y cultural; en otras palabras, se comportan con un enfoque sostenible, come comprueban varios autores (Rotherham, 2007; Pilgrim, 2010). De hecho, todos los elementos naturales y humanos que construyen el entorno no son piezas triviales de un espacio genérico, sino herramientas territoriales específicas para la composición y la formación de una cierta identidad espacial. Estos elementos en sí mismos están llenos de significados culturales y religiosos, y se convierten en íconos de cualquier experiencia específica y en herramientas para una relación inclusiva entre material e inmaterial, tangible e intangible, sagrado y profano (Knott, 2015).

Piedras, árboles, letreros, comidas y bebidas, canciones y poemas - en una palabra, patrimonio o heritage - contribuyen a crear, desarrollar y entregar, a una escala tanto pequeña como grande, una imagen más o menos fuerte de un lugar y de las acciones rituales que se dan en ello. Esto es definible como una mezcla de percepción, visualización e imaginación, porque un lugar y un paisaje son al mismo tiempo una expresión del pasado, de acciones y relaciones que solían aparecer, y una experiencia, que es un deseo, una proyección de/para el futuro, un plan, una imagen tal como es percibida, deseada o simplemente imaginada.

Cresswell (2004: 74-76), precisamente habla de "lugares de identidad y del sentido de lugar" y de "lugares de eventos": un lugar es el resultado de una cultura y de su tarea de preservar los rastros del pasado, que puede estimular un patrimonio cultural con un fuerte y específico sentido de identidad. Por otro lado, Pistocchi (2009) y Prieur (2006: 14) argumentan que el paisaje es una parte familiar de la escena cotidiana de todos y tiene un papel en el sentido de pertenencia de las personas a un lugar en particular y a una comunidad en particular; entonces, en un nivel consciente o incluso inconsciente, contribuye al bienestar de la mente ${ }^{7}$. Esto puede describir claramente el desempeño tanto de los peregrinos como de los turistas hacia el respeto de la integridad territorial, singularidad cultural y sostenibilidad ambiental. Por lo tanto, en una experiencia turística como es una peregrinación o una ruta cultural, el medio ambiente no es necesariamente un destino natural o una atracción vacía de significado: eso es parte de un área sistémica e integral que puede definirse como un paisaje inclusivo (Azzari y Dallari, 2018).

Cuando conectamos la práctica del turismo con la naturaleza y el medio ambiente, generalmente pensamos en el ecoturismo. Wearing et al. (2010: 82) hablan de tres enfoques diferentes de la relación entre el "yo" (un turista) y la naturaleza: el primero, y probablemente el más superficial, es proteger la naturaleza para proteger a la humanidad: significa que la naturaleza es importante con respecto a los humanos (un punto de vista bastante egoísta y antropocéntrico); otro enfoque reconoce que la naturaleza y todos los seres humanos "sintientes" son capaces de probar placer y dolor, y deben ser considerados como sujetos legales (un punto de vista bastante ideológico y moralista); el último enfoque (el más "extremo") nos lleva al eco-centrismo y, consecuentemente, a una lógica ecoturística: considera la naturaleza como algo real y verdadero, un "lugar-espacio" donde los seres humanos están conectados con la vida.

Los peregrinos no son egoístas, ni ideológicos o moralistas y tampoco extremos. Según esta visión, el medio ambiente (sistema de propiedades naturales) se percibe como sagrado, religioso y atemporal, como expresión de un equilibrio dinámico eterno de todo el ecosistema. Hilo conductor de los tres es que un buen ambiente se vuelve importante para todas las tipologías de turismo: un lugar urbano agradable, o un espacio natural no contaminado, atraen a turistas

7 Traducción desde el original en inglés. 
urbanos y culturales, así como a turistas de masas, excursionistas, ciclistas, etc., debido no necesariamente a un recurso turístico específico o a una atracción espiritual o cultural, sino sólo a un paisaje seguro, agradable y pacífico. Inclusive, dentro de esta relación experiencial y mental entre las personas y el paisaje, los sentidos de la vista, el gusto, el oído, el olfato y el tacto, todos estos elementos se viven con una mirada sagrada (Morgan, 2005; Dallari, 2016).

Tomando en cuenta lo afirmado hasta este momento, es necesario entonces identificar indicadores específicos basados en mediciones cuali-cuantitativas y estadísticas de las condiciones ambientales, que sean trazables a lo largo del tiempo y puedan, por un lado, describir un territorio y monitorear sus desempeños de sostenibilidad (por ejemplo, un paisaje natural y cultural) y, por el otro, protegerlo y promoverlo para su desarrollo turístico. Se han realizado muchas propuestas para medir la sostenibilidad en términos cuali-cuantitativos, derivadas de obras fundamentales como Nordhaus y Tobin's (1972), el Informe Brundtland (1987) y la Cumbre de Río de Janeiro (1992). Si bien estas cuestiones se hayan desarrollado a lo largo de las últimas tres décadas, su aplicación en la escala local ha sido escasa, especialmente porque las instituciones locales a menudo encuentran dificultades para aplicar el gran conjunto de indicadores e índices propuestos. Por ejemplo, el Índice de Sostenibilidad Ambiental (ESI) abarca 5 dominios compuestos por 76 variables: sistemas ambientales (aire, tierra, agua, biodiversidad), reducciones de tensiones ambientales (contaminación del aire, presión de los desechos, gestión de recursos naturales), vulnerabilidad humana (exposición de habitantes a disturbios ambientales), capacidad social $e$ institucional (su capacidad para fomentar respuestas efectivas a los desafíos ambientales) y Global Stewardship (cooperación con otros países en la gestión de problemas ambientales comunes) (Stiglitz et al., 2009).

Ya sea que hablemos de "ecoturismo" o de turismo a lo largo de itinerarios o rutas de peregrinación, vemos una estrecha relación con la naturaleza. Si, por lo tanto, se intenta "turisticizar" un área, es necesario formular, de manera preliminar, un análisis territorial detallado, aún más si se trata de un entorno natural, con el uso de herramientas más ad hoc para el territorio. Por esta razón, en el 2016 La Comisión Europea preparó el documento "El sistema europeo de indicadores del turismo. Toolkit ETIS para la gestión sostenible de los destinos", en donde se individúan 23 indicadores principales y 40 opcionales (a discreción de la realidad turística específica), agrupables en 4 categorías (gestión de destinos, impacto social y cultural, valor económico, impacto ambiental). Todos llaman una vez más a la sostenibilidad y la conectan, indirectamente, también con la experiencia turística de los itinerarios, que representan un punto de referencia para las políticas territoriales (turísticas, económicas, ambientales) actuables y actuadas también en el contexto italiano.

\section{El marco empírico italiano}

En Italia, según los datos de IPR Marketing, contenidos en el $6^{\circ}$ Informe Los italianos, el turismo sostenible y el ecoturism $\mathrm{o}^{8}$, la sostenibilidad se está convirtiendo en una palanca para nuevas formas de turismo vivencial en contacto con la naturaleza y las comunidades locales. El país se está moviendo hacia la dirección de la sostenibilidad ambiental y social (territorial) en relación con la promoción de estas "nuevas" actividades turísticas. Estudios de caso $^{9}$ realizados en los últimos tiempos muestran una mayor disposición a seguir caminos

$86^{\circ}$ Rapporto "Gli italiani, il turismo sostenible e l'ecoturismo“, Fondazione Univerde.

9 Por ejemplo, muchas personas practican, o les gustaría vivir, una nueva experiencia de peregrinación junto con animales de granja, como caballos o burros (estos últimos para senderos más cortos). De hecho, ,el ,ecui-tourismo“ es una de las opciones que mejor permite aprovechar el paisaje de una forma más íntima y natural, para despertar esas emociones en el turista que sólo el caballo puede transmitir" (Bambi et al., 2015: 593). Desafortunadamente, todo esto encuentra obstáculos, especialmente debido al alto costo de mantener al animal y la ausencia de estructuras específicas a lo largo de los caminos. Sin embargo, los ejemplos de Europa son reconfortantes, tanto para las nuevas peregrinaciones (a partir de la experiencia de Santiago de Compostela) como para el turismo ambiental rural (desde Irlanda, donde la cultura ecuestre del territorio se ha relacionado con iniciativas públicas y privadas) (Ibíd., 2015). 
virtuosos de sostenibilidad al elegir algunos indicadores significativos desde una amplia gama, aplicados en contextos de paisajes con un enfoque práctico local de sostenibilidad (Castiglioni, De Marchi, 2007).

Según esta lógica, a través del Proyecto Cammini e Percorsi $2017^{10}$ se está tratando de promover el descubrimiento de territorios y destinos menores, a través de una movilidad dulce / lenta (a pie, en bicicleta, a caballo) a lo largo de itinerarios históricos tanto locales como interregionales, con un doble objetivo: promover el patrimonio cultural "menor" y proteger los ecosistemas, a menudo desfavorecidos por negligencia o falta de dinero, factores generalmente relacionados con el abandono de estas áreas periféricos por comunidades humanas. Para ello, es esencial identificar y planificar: puntos de inter-modalidad e intercambio; puntos de accesibilidad; zonas de amortiguamiento; etapas.

De acuerdo con el documento El turismo lento y sostenible de los caminos, paradigma del turismo responsable ${ }^{11}$, el año 2016 se registraron al menos 40.000 visitantes en el tramo de la Vía Francigena. Esta información, analizada por la Asociación Europea, a través de una encuesta hecha a sus "peregrinos", muestra que se trata de un viaje, que involucra a todos los grupos de edad, de 16 a 75 años, con un aumento en la asistencia de personas con más de 70 años y un fuerte aumento de las con menos de 20 años en comparación con 2015. Las fajas más representadas están entre 40 y 60 años $(41 \%)$ de edad; a continuación, se encuentran a personas entre los 30-40 y 20-30 años. La mayoría de los peregrinos se mueven a pie $(79 \%)$, mientras que otros usan la bicicleta, y no solamente por motivos religiosos: "una de las verdaderas motivaciones es la de 'saber cómo perder el tiempo', considerada hoy en la sociedad moderna casi inapropiada, porque siempre estamos tratando de recuperar el tiempo que nos falta. Surge en estas experiencias la espiritualidad, el conocimiento del Yo y la investigación íntima que nos acerca a la naturaleza y el entorno que nos rodea. La Vía Francigena ofrece un tiempo para reflexionar, pensar, descubrir, donde el aspecto cultural es igualmente importante: el camino reserva un viaje a través de la historia, el tiempo y la cultura europea ${ }^{12}$.

Los Apeninos de Emilia-Romagna, por donde se desarrolla una parte importante de la Vía Francigena, y cruzados por 14 rutas de peregrinos, están protegidos a lo largo de su cresta, debido a su posición geográfica de conexión entre el Norte y el Sur de Italia. En esta misma porción de territorio (y región administrativa), poco distante de la Vía Francigena ${ }^{13}$ se encuentra el Parque Nacional de las Florestas Casentinesi - Monte Falterona - Campigna, igualmente atravesado antiguamente por otras vías "Romeas" (Vía Germanica, Vía Romea Strata), que conectaban y flanqueaban el eje principal de la Vía Francigena (Mapa 2). En el espacio incluido entre estas tres Romeas se inserta el parque, un área protegida en los Apeninos que queda entre las regiones de Emilia-Romaña y Toscana, cubriendo más de 36 hectáreas, y que en este artículo se presenta como ejemplo de buenas prácticas aplicadas al territorio y a su desarrollo en clave turística. El Parque se encuentra prevalentemente dentro del territorio de la región Emilia-Romagna, conocida por ser el primer destino de turismo de playa en Italia y una de los más importantes de Europa.

En el año 2016 la Región Emilia-Romagna reconoció 14 caminos religiosos, incluyendo la Vía Francigena, el de San Francisco, la Romea Germánica y el Camino de San Antonio (Vie di Pellegrinaggi, 2016). En respuesta a esta formalización, los servicios de la Agencia de Promoción Turística de Emilia-Romagna (APT Servizi) planificaron protocolos para la sostenibilidad

10 Promovido por la Agenzia del Demanio, el Ministerio de Patrimonio Cultural, Actividades y Turismo y el Ministerio de Infraestructuras y Transporte, en colaboración con los otros organismos que participan en la iniciativa con bienes inmuebles de propiedad - Anas, SpA, Municipios, Provincias, Regiones - y de acuerdo con las Administraciones competentes.

11 Dragone, A. (2017). Il turismo lento e sostenibile dei cammini, paradigma del turismo responsabile, AITR y Terre di mezzo Editore.

12 http://www.viefrancigene.org/it/resource/news/chi-si-mette-cammino-sulla-francigena-analisi-e-ri/.

13 La vía que conducía los peregrinos "Romei", los directos a Roma, y también los peregrinos "Ierosolimitani" directos a Jerusalén. 


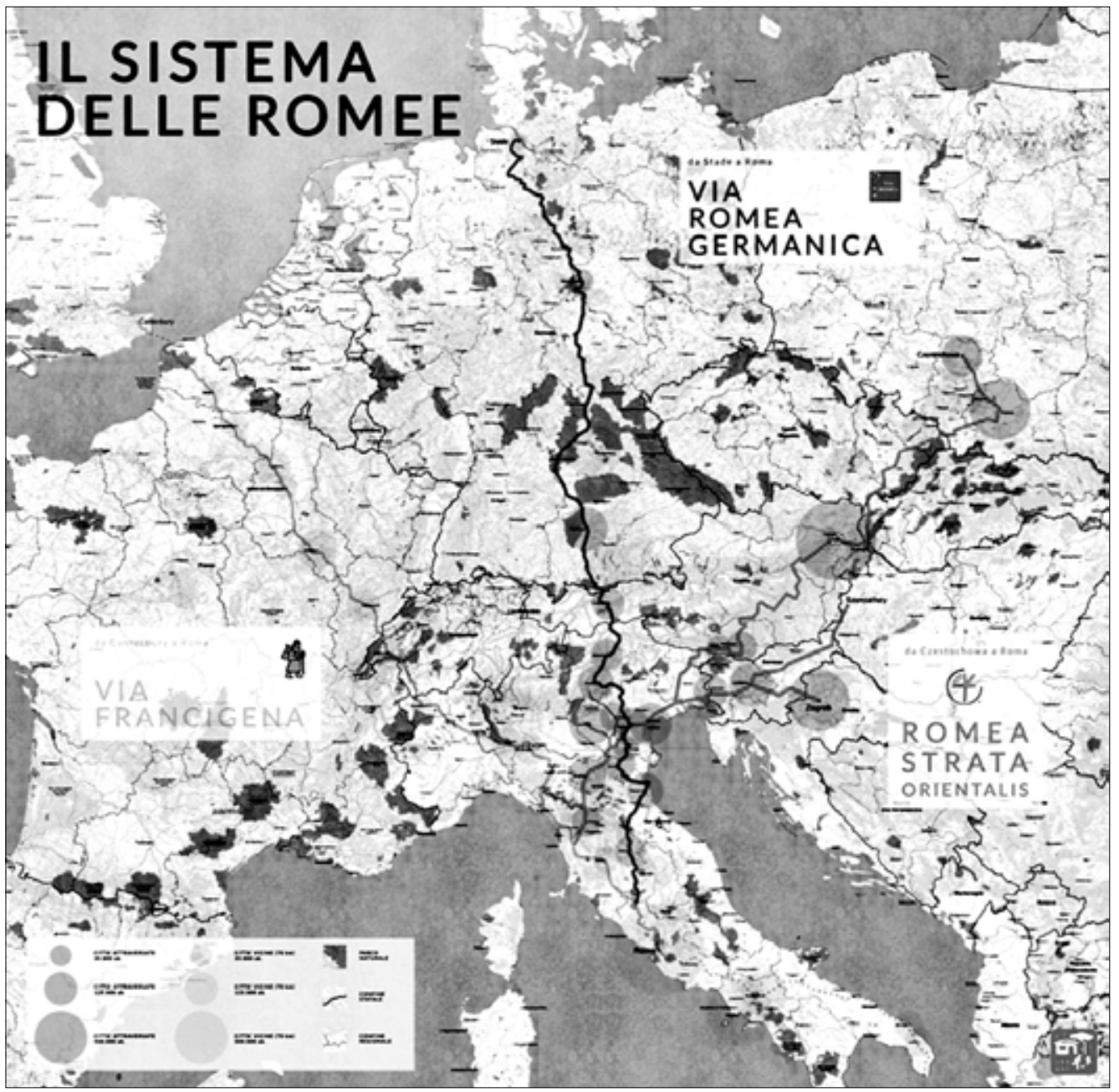

MAPA 2. El sistema europeo de las Vías Romeas.

FUENTE: HTTP://WWW.VIAROMEAGERMANICA.COM/NEWS/PIEDI-ITALIA-LA-VIA-FRANCIGENA-LA-VIA-ROMEAGERMANICA-MILANO/ 


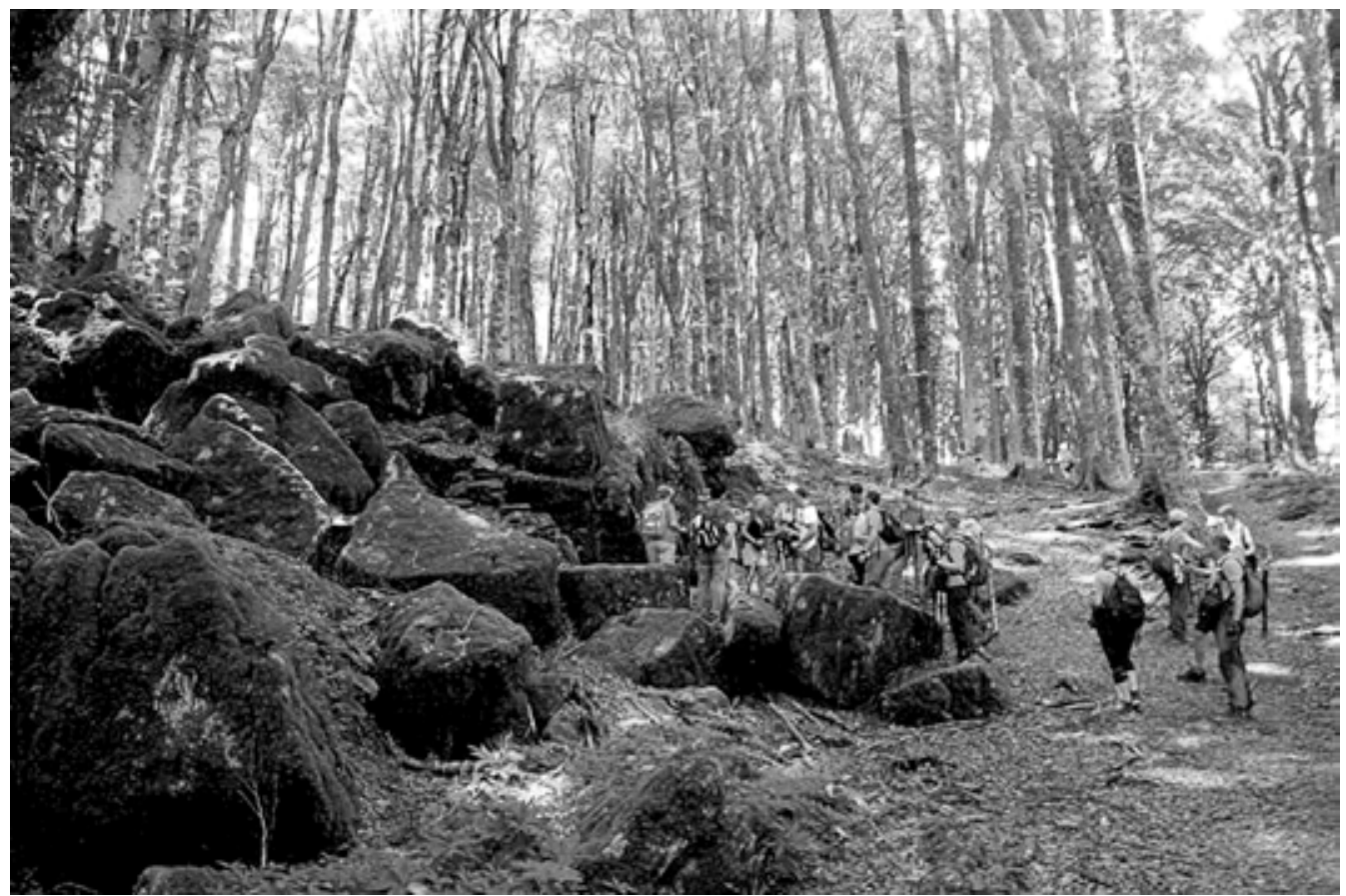

FOtO 1. Excursionistas en el Parque Nacional de las Florestas Casentinesi. Fuente: www.forlì24ore.it.

ambiental de los aspectos del alojamiento (residuos, consumo de agua y energía, emisiones de $\mathrm{CO} 2$, alimentos biológicos, y otros). El proyecto se desarrolla en una vasta área geográfica y se considera un modelo bueno y fácil de aplicar por otras instituciones en el ámbito de las peregrinaciones.

A principios de la Edad Media los monjes remodelaron y mantuvieron el área para incluir significados simbólicos (por ejemplo, el color blanco claro de los árboles, con el propósito de guiar a los peregrinos y los animales a la salvación). Recién, y con bastante evidencia, ha surgido la necesidad de unir el interés religioso con el ambiental en la protección de esta área. Por lo tanto, en los últimos años, refiriéndose a las indicaciones y políticas europeas y regionales como marco de referencia para la sostenibilidad y sustentabilidad del territorio (Hábitat, Red Natura 2000, LIFE, Lugar de Importancia Comunitaria, Área Especial de Conservación, Área de Protección Especial, Directiva Aves), la Autoridad del Parque ha llevado a cabo estudios e investigaciones con el objetivo de monitorear el status quo de la flora y la fauna, así como la estabilidad e integridad general de la zona (Casentinesi Forest National Park, 2014).

Se catalogaron todos los hábitats, según los criterios europeos (HABITAT, 2010), se calculó la biodiversidad (presencia o ausencia de biotipo) y analizaron y enumeraron todas las especies de árboles y plantas (con una precisión al metro cuadrado), su posición, su distribución (densidad) y su relación con todas las especies de fauna, tratando de resaltar el umbral crítico y llegar a la evidencia de las causas del estrés ambiental, e involucrando en ciertas operaciones también los turistas y peregrinos. De acuerdo con el uso de la tierra en cada sección, las actividades rurales y turísticas son limitadas, y otras acciones como la cría y la caza están prohibidas.

A pesar de los riesgos y cambios generales, debidos al cambio climático mundial actual y a las actividades antrópicas pasadas, la presencia de peregrinos y excursionistas ha aparecido como una experiencia favorable para el desarrollo sostenible del territorio. 


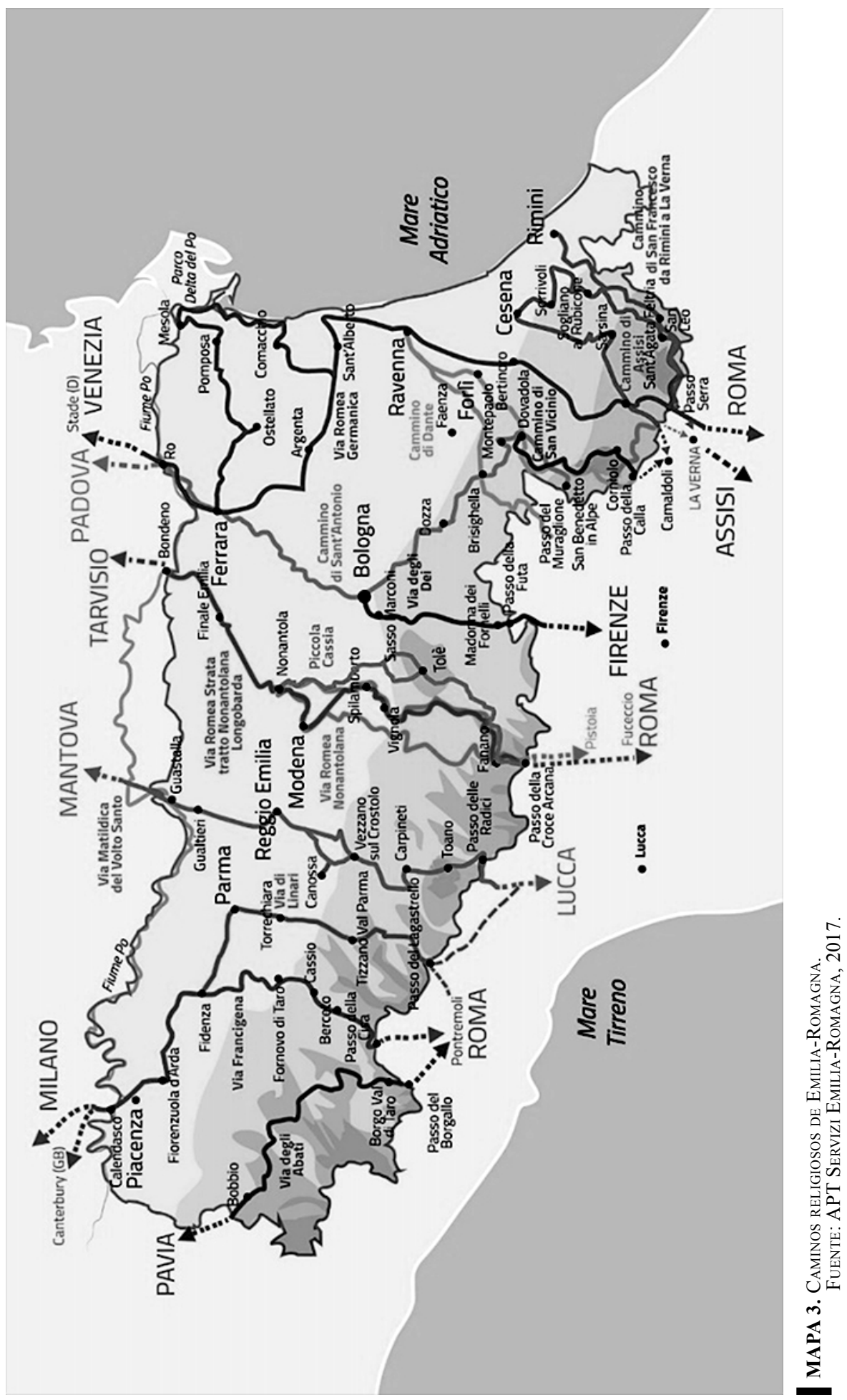


La gestión de esta área protegida hace referencia a las tres fases de la Carta Europea para el Turismo Sostenible en Âreas Protegidas (2010): implementación de las áreas protegidas, participación de empresas locales de turismo y promoción por parte de los operadores turísticos. El estado actual del arte del parque se encuentra en la Fase 1, que prevé el análisis del ecosistema a través de formas de autocontrol y la formación de grupos de trabajo como "comida y vino", "senderismo", "educación" y "cultura" para fomentar el desarrollo de un cierto tipo de turismo y seguir apoyando a las manifestaciones sostenibles como el turismo de peregrinación. El grupo de trabajo "cultura" está a cargo de la promoción de los tres caminos religiosos a través del área, en cooperación con las tres rutas de peregrinación que la cruzan.

Estas realidades siguen más o menos el trend de las demás en territorio italiano frente del gran reto de volverse experiencias no solamente turísticas, sino geográficamente efectivas. A menudo las áreas involucradas, generalmente más periféricas, ya han experimentado formas de abandono de parte de la población residente autóctona y su vuelta para abrir actividades económicas sostenibles no siempre es tarea sencilla para desempeñar. Además, los últimos años también el grado de "turisticidad" de las áreas protegidas ha visto una pequeña bajada", lo que puede empeorar ulteriormente el nivel de atención de parte de la política y generar un proceso de degradación del territorio en términos ambientales y también socio-económicos y culturales. Esto explica entonces la atención demostrada también por Italia y la Región EmiliaRomagna para conjugar las políticas ambientales con las turísticas, en particular con respecto a los itinerarios eco-culturales, que son los menos dañinos para el medio ambiente y los que, retomando el modelo de los peregrinos históricos, están viviendo a nivel global un fuerte crecimiento, tanto por "moda" como por imitación de estilos o por sencillo interés o curiosidades personales (Reader, 2007).

\section{Conclusiones}

Los peregrinos formales e informales, y los turistas que "caminan", se dedican a la naturaleza, a la esfera social y a los valores básicos comunes de la sostenibilidad y protección del medio ambiente. A partir de esta afirmación, en base a la literatura académica oficial sobre políticas e indicadores de desarrollo sostenible (Hammond y World Resources Institute, 1995; Kates et al., 2005), que también se aplican al turismo, y con un enfoque cualitativo que es tanto interdisciplinario como intercultural (Mendoza y Prabhu, 2003; Miller, 2001; Choi y Turk, 2011), se ha propuesto una lectura de unos casos en el ámbito europeo e italianos en términos de buenas prácticas turística actuadas en el territorio en base a las políticas empujadas por los organismos institucionales internacionales (Lehtonen, 2004) en tema de desarrollo territorial sostenible, y en particular en el marco del turismo de peregrinación. De hecho, desde hace algún tiempo ha surgido una perspectiva común sobre los valores culturales del territorio y las ideas del cambio actual hacia la llamada "transición socio-ecológica" (Folke, 2006; Smith y Stirling, 2010), que se han valorado como un paradigma de una sostenibilidad emergente (Clark \& Dickson, 2003).

Las experiencias descritas han usado protocolos de sostenibilidad que se han concretado en una aplicación efectiva a nivel de manejo del territorio y su directa valorización, como lo confirman Adrian Ivakhiv (2013) y Kinsle (1995), que definen la peregrinación como ecológicamente sostenible y relacionada con el movimiento más amplio de la "ecologización de la religión", que en los últimos años hizo las prácticas de peregrinación tradicionales más sostenibles (Rigby, 2000). Desde el breve análisis realizado emerge como el patrimonio sagrado y los paisajes sagrados se puedan usar como herramientas científicas en este ámbito, ya que proporcionan una ayuda a arrojar luz sobre las relaciones de convergencia y divergencia entre la peregrinación y el turismo (Cohen, 1992) en sus formas más o menos eco-compatibles y sostenibles con respecto a

$14 \mathrm{http} / /$ annuario.isprambiente.it/entityada/basic/6463/singola. 
la salud del territorio. En otras palabras, gracias a este enfoque es posible evaluar el papel de los peregrinos y proporcionar respuestas al delinear la diferencia entre los "turistas posmodernos" y los "peregrinos", y entre los ecoturistas y los peregrinos en las zonas rurales, que son, como visto, un factor esencial para un desarrollo turístico local sostenible y manifestación de un estilo de vida eco-compatible en el ámbito turístico.

La peregrinación es hoy en día una práctica cada vez más "buena" y eficaz en apoyo a la transición socio-ecológica. Los peregrinos formales e informales se dedican al medio ambiente, percibido como un paisaje, e incluso un paisaje sagrado, a través de experiencias individuales continuas y permanentes. Por esta razón los peregrinos religiosos y los peregrinos culturales modernos son los protagonistas de la protección sostenible del medio ambiente (lo que surge al comparar eco-turistas y peregrinos formales e informales). El paisaje sagrado, el corazón visible del entorno, puede entonces evaluarse como un concepto que supera la dicotomía de lo tangible e intangible y convierte a peregrinos y viajeros en outsider proactivos con respecto a un estilo de vida sostenible, que contribuye en gran medida a un desarrollo local innovador, creativo y sostenible, y a un "ecological-social change" dentro del desarrollo turístico y territorial.

En base a estas conclusiones, los autores coinciden en que el paisaje cultural (en su complejidad) podría valorarse como un fenómeno holístico e inclusivo sostenible, de acuerdo con las acciones políticas de la UNESCO, además del Consejo Europeo y la Convención del Paisaje Europeo. Los organismos internacionales y locales, junto con las redes de asociaciones de peregrinos, dan a conocer cómo los sitios sagrados y las rutas de peregrinación son el resultado de importantes señales sociales para las comunidades locales y las identidades dentro del contexto mundial. Por otro lado, el redescubrimiento y la renovación de la peregrinación tradicional, que se han vuelto a dar con fuerza a partir de finales del siglo XX en el contexto europeo, han puesto de manifiesto que los valores sagrados comunes de la espiritualidad y las motivaciones de sostenibilidad también forman parte de las prácticas experienciales. Asimismo, la participación socio-local es fundamental, integrando las actividades rurales con las necesidades de los peregrinos / turistas, las curiosidades y la sensibilidad de ambas partes integrándolas, además de prestar atención al paisaje, a su cuidado, y a las prácticas y experiencias vivenciales directas del peregrino.

Como se demostró anteriormente, una condición favorable de sostenibilidad ambiental, basada en indicadores precisos de cuidado ambiental y participación social, se encuentra en las áreas protegidas de montaña como es el Parque Nacional de las Florestas Casentinesi en la Región Emilia-Romagna, donde los peregrinos, y el territorio en su conjunto, encuentran las condiciones ideales para implementar la sostenibilidad turística mientras que se busca y practica concretamente la sostenibilidad del medio-ambiente.

Cada vez más a menudo, itinerarios religiosos y culturales (Briedenhann y Wickens, 2004), así como muchas de las peregrinaciones europeas (Santiago de Compostela, Via Francigena con la Asociación Europea "Vie Francigene", algunas de las ciudades de las Vías Romee y pueblos rurales a lo largo de estas rutas), están promulgando comportamientos y políticas sostenibles, con una mayor atención al medio ambiente, a la cultura local y a la participación social. Este interés reciente lo atestigua el Proyecto Sostenible Via Francigena, un modelo de sostenibilidad y accesibilidad, con un nivel internacional, desde Canterbury hasta Roma. Estas prácticas, realizadas a escala local, pero con una visión global, están aumentando en las experiencias de las nuevas peregrinaciones actuales, que son testigos de un comportamiento consciente, ético y sostenible del turista y promueven "naturalmente" un desarrollo territorial local integrado, integrante y sostenible, y con la capacidad de hacerlo continuativo en el tiempo a beneficio también de las generaciones futuras. 


\section{Agradecimiento}

Se agradecen: el Comité Científico de la Asociación Europea "Vie Francigene" (Eavf Sc), el Center for Advanced Studies in Tourism (Cast) de la Universidad de Bologna (Italia), el network Unesco/Unitwin "Culture, Tourism, Development", el Team delle Cattedre Unesco Italiane "Assetto del Territorio, Sostenibilità urbana, Turismo" (TEST).

\section{Bibliografía}

Alighieri, D. 1965, "Vita nova. Florence", en: www.liberliber.it/mediateca/libri/a/alighieri/vita_nuova_edizione_ barbera/html/testo.htm

Azzari, M. y Dallari, F. 2018, "Le vie romee dell'europa e del mediterraneo di viandanti, pellegrini e mercanti. le strade dell'identità europea nelle pratiche contemporanee", en: Salvatori, F., Atti del XXXII Congresso Geografico Italiano. L'apporto della geografia tra rivoluzione e riforme”, Sgi, Roma.

Almatourism. 2018, Sacred landscape: an invaluable resource between knowledge and sustainable local tourism development, vol 9, No 8 .

2017b, Romei and Francigeni. The Sources for an European Pilgrimage History, Vol. 8, N. 16.

2017, The Via Francigena: the Long Way of Peace among the European Landscapes, Vol. 8, Nº 6

Badone, E. 2014, "Conventional and Unconventional Pilgrimages: Conceptualizing Sacred Travel in the Twenty-first Century", en: Pazos A. M. (Ed.), Redefining Pilgrimage. New Perspectives on Historical and Contemporary Pilgrimages, Ashgate, Burlington, USA, pp. 7-31.

Briedenhann J., Wickens E. 2004, "Tourism routes as a tool for the economic development of rural areas. Vibrant hope or impossible dream?", en: Tourism management, N 25(1), pp. 71-79.

Brukner M. 2001, Sette passi sul cammino di Santiago, Editrice Mediaevo, Bologna.

Brundtland G. H. 1987, "Our common Future, World Commission on Environment and Development", en: http:// www.un-documents.net/our-common-future.pdf

Castiglioni B., De Marchi M. 2007, "Paesaggio, Sostenibilità Valutazione", Quaderni del Dipartimento di Geografia, 24, Università di Padova,.

Cavaliere F. 2015. "Arte e devozione nei santuari mariani del Salento meridionale lungo il cammino per Santa Maria de Finibus Terrae", en: Trono, A. et al. (Eds.), In viaggio verso Gerusalemme: Culture, Economie e Territori - Walking towards Jerusalem: Cultures, Economies and Territories, Lecce, Mario Congedo Editore, pp. 231- 249.

Choi, H. C. y Turk, E. S. 2011, "Sustainability indicators for managing community tourism", en: Quality-of-life community indicators for parks, recreation and tourism management, Springer, Dordrecht, pp. 115-140.

Clark, W. C., \& Dickson, N. M. 2003, "Sustainability science: the emerging research program", en: Proceedings of the national academy of sciences, $\mathrm{N}^{\circ} 100$ (14), pp. 8059-8061.

Cohen, E. 1992, "Pilgrimage and tourism: Convergence and divergence", en: Morinis, E. A. Sacred journeys: The anthropology of pilgrimage, Praeger Editors, Westport, pp. 47-61.

Collings-Kreiner N. 2014, "Pilgrimage and Mobilities: The 'pilgrimage Turn' within the 'New Mobilities Paradigm", en: Lois-González et al. (Eds.), New Tourism in the 21st Century: Culture, the City, Nature and Spirituality, Cambridge Scholars Publishing, pp. 33-54.

$2010^{\mathrm{a}}$, "Researching Pilgrimage: Continuity and Transformations", en:Annals of Tourism Research, 37/2, pp. 440-456.

2010b, "The geography of pilgrimage and tourism: Transformations and implications for applied geography", en: Applied geography, N 30(1), pp. 153-164.

Collins-Kreiner, N. et al. 2017, Christian tourism to the Holy Land: Pilgrimage during security crisis, Routledge.

Corinto, G. 2017, "Food and Gastronomic Tourism for Developing Rural Areas Around the Via Francigena in Tuscany", en: Almatourism - Journal of Tourism, Culture and Territorial Development, 8(6), pp. 106-122. doi:https://doi.org/10.6092/issn.2036-5195/6228

Cosgrove, D. 1984, Social Formation and Symbolic Landscape, Croom Helm, London.

Cresswell, T. 2003, "Landscape and the obliteration of practice", en: Anderson, K. et al. (Eds.), Handbook of Cultural Geography, Sage, London, pp. 269-81.

2004, Place: A Short Introduction, Oxford, Blackwell. 
Council of Europe. 2000, European Landscape Convention, 2000, en: www.coe.int/en/web/landscape/home

Dallari, F. 2016, "The Heritage from Cultural Turn to Inclusive Turn. The Cultural and Sacred Landscapes of the UNESCO List: a Sustainable Track to overcome the Dichotomy between Tangible and Intangible Heritage?", en: Bassa L., F., Kiss (Eds.), Proceedings of TCL2016 Conference 'Tourism and Cultural Landscapes: Towards a Sustainable Approach, Foundation for Information Society (INFOTA, en: http:// tcl.infota.org/proceedings/articles/Proceedings_TCL2016.pdf

2016 , "The Heritage from Cultural Turn to Inclusive Turn. The Cultural and Sacred Landscapes of the UNESCO List: a Sustainable Track to overcome the Dichotomy between Tangible and Intangible Heritage?", PROCEEDINGS OF TCL2016 CONFERENCE, INFOTA, pp. 129-141, http://infota.org/wpcontent/uploads/2017/01/Proceedings_TCL2016.pdf.

2012b, "Territorial Management of Italian Catholic Church: between Pilgrimages and Religious Culture", en: European Journal of Tourism, Hospitality and Recreation, 3/2, pp. 109-134.

2007, "Distretti turistici tra sviluppo locale e cooperazione interregionale", en: Bencardino, F. y M., Prezioso, Geografia del turismo, McGraw-Hill, Milano.

Dallari, F., Gola, A. 2012a "The urban development of religious tourism destinations between sacred and profane: the cases of Lourdes and San Giovanni Rotondo", en: Trono, A. (a cura di), Sustainable Religious Tourism. Commandments, Obstacles \& Challenges, Edizioni Esperidi, Monteroni di Lecce (LE), pp. 275291

Dallari, F., y Mariotti, A. 2017, "Editorial”,Almatourism - Journal of Tourism, Culture and Territorial Development, 8(6), I-V. doi:https://doi.org/10.6092/issn.2036-5195/6673

2006, Il turismo tra sviluppo locale e cooperazione interregionale, Patron, Bologna.

Dallari, F. y Niglio, O. 2018, "Editorial", Almatourism - Journal of Tourism, Culture and Territorial Development, $\mathrm{N}^{\circ} 9$ (8), I-IV. doi:https://doi.org/10.6092/issn.2036-5195/8181

Dallari, F. et al. 2009, I viaggi dell'Anima. Società, Culture, Heritage e Turismo, Patron, Bologna.

Dallari, F. et al. 2018, "European and Global Perspectives on Sacred Landscape", Almatourism - Journal of Tourism, Culture and Territorial Development, N${ }^{\circ}$ (8), pp. 252-256. doi:https://doi.org/10.6092/ issn.2036-5195/8182

Dann, G. M. 1981, "Tourist motivation an appraisal”, Annals of tourism research, N 8 (2), pp. 187-219.

Dragone, A. 2017, Il turismo lento e sostenibile dei cammini, paradigma del turismo responsabile, AITR y Terre di mezzo Editore.

Emilia-Romagna. 2016, "Vie di Pellegrinaggi", en: http://www.emiliaromagnaturismo.it/it/vie-dipellegrinaggio/vie-pellegrinaggio-primo-piano.html

Erkuş-Öztürk, H., \& Eraydın, A. 2010, "Environmental governance for sustainable tourism development: Collaborative networks and organisation building in the Antalya tourism region", en: Tourism management, $\mathrm{N}^{\circ} 31(1), \mathrm{pp} .113-124$.

European Institute of Cultural Routes, http://culture-routes.net/cultural-routes.

Folke, C. 2006, Resilience: "The emergence of a perspective for social-ecological systems analyses", Global environmental change, N 16 (3), pp. 253-267.

Gonzaléz-Paz C. (Ed.) 2015, Women and Pilgrimage in Medieval Galicia, Ashgate, Burlington.

Hammond, A. y World Resources Institute. 1995, Environmental indicators: a systematic approach to measuring and reporting on environmental policy performance in the context of sustainable development (No. 333.7/H225), World Resources Institute, Washington, DC.

ICCROM. 2003, Conservation on Living Religious Heritage, en: www.iccrom.org/ifrcdn/pdf/ICCROM ICS03_ReligiousHeritage_en.pdf

ICOMOS. 2005, Resolution of the 15th General Assembly for the „establishment of an International Thematic Programme for Religious Heritage“, en: www.icomos.org/xian2005/resolutions15ga.htm

2011, "17th General Assembly regarding the protection and enhancement of sacred heritage sites, buildings and landscapes", en: http://whc.unesco.org/uploads/activities/documents/activity-646-1.pdf

IUCN/MAB's UNESCO. 2012, "Sacred Natural Sites. Guidelines for Protected Area Managers", en: www. iucn.org/content/sacred-natural-sites-guidelines-protected-area-managers-0

IUCN/UNESCO. 2008, "Sacred Natural Sites. Guidelines for Protected Areas Managers", en: https://cmsdata. iucn.org/downloads/pa_guidelines_016_sacred_natural_sites.pdf

Ivakhiv, A. 2013, "Green Pilgrimage: Problems and Prospects for Ecology and Peace-Building" en: Pazos A. M. (Ed.), Pilgrims and Pilgrimages as Paecemakers in Christianity, Judaism and Islam, Ashgate, Farnham, pp. 85-103. 
Kates, R. W. et al. 2005, "What is sustainable development? Goals, indicators, values, and practice", Environment, Washington DC, N 47 (3), pp. 8-21.

Knott, K. 2015, The location of religion: A spatial analysis, Routledge.

Lehtonen, M. 2004, "The environmental-social interface of sustainable development: capabilities, social capital, institutions", Ecological economics, N 49 (2), pp.199-214.

Lois-González, R. C., Santos Solla M.X. 2014, "New trends in Urban and Cultural Tourism: the Model of Santiago de Compostela", en: Lois-González R. C. et al. (Eds.), New Tourism in the 21st Century: Culture, the City, Nature and Spirituality, Newcastle upon Tyne, Scholars Publishing, Cambridge , pp. 209-234.

Minkenberg, M. 2002, "Religion and public policy: institutional, cultural, and political impact on the shaping of abortion policies in Western democracies", Comparative Political Studies, N 35(2), pp. 221-247.

Mitchell, W. J. T. 1994, Imperial landscape, en: Mitchell W. J. T. (Ed.), Landscape and Power, University of Chicago Press, Chicago, pp. 5-34.

Mendoza, G. A. y Prabhu, R. 2003, “Qualitative multi-criteria approaches to assessing indicators of sustainable forest resource management”, Forest ecology and management, N! 174(1-3), pp. 329-343.

Miller, G. 2001, "The development of indicators for sustainable tourism: results of a Delphi survey of tourism researchers", Tourism management, N 22 (4), pp. 351-362.

Morgan, D. 2005, The sacred gaze: Religious visual culture in theory and practice, University of California Press, Berkeley.

Morinis, E. A. 1983, "Pilgrimage and tourism", Annals of Tourism Research, N 10 (4), pp. 569-570.

Nannini, S. 2017, "The Future of Churches - Identity System for the Valorization of Local Contexts", Almatourism - Journal of Tourism, Culture and Territorial Development, 8 (6), pp. 188-190. doi:https://doi.org/10.6092/ issn.2036-5195/6666

Niglio, O. 2018, "Sacred Landscape for a Global Approach", Almatourism - Journal of Tourism, Culture and Territorial Development, 9(8), pp. 1-16. doi:https://doi.org/10.6092/issn.2036-5195/7913

Nordhaus, W.D., Tobin, J. 1972, "Is Growth Obsolete? New York", Economic Growth, National Bureau of Economic Research, 96.

Parco Nazionale delle Foreste Casentinesi. 2014, Rete Natura 2000 - Misure Specifiche di Conservazione.

Park, C. 1994, Sacred Worlds. An Introduction to Geography and Religion, Routledge, London.

Pistocchi, F. 2009, "Ancestor Graves. Rediscovering and Promoting Bunce Island as a Slave Site, Sierra Leone", en: Trono, A. (Ed.),Tourism, Religion and Culture. Regional Development through Meaningful Tourism Experiences, Proceedings of the International Conference, Lecce, Mario Congedo Editore, pp. 667-686.

Prieur, M. 2006, "Landscape and social, economic, cultural and ecological approaches", en: AA.VV., Landscape and sustainable development. Challenges of the European Landscape Convention, Council of Europe Publishing, pp.11-28.

Pungetti, G. et al. (Eds.) 2012, Sacred species and sites: Advances in biocultural conservation, Cambridge University Press, Cambridge.

Pungetti, G. 2018, "Spiritual Values of Landscape for a Recomposition between Nature and Culture", Almatourism - Journal of Tourism, Culture and Territorial Development, 9(8), pp. 17-31. doi:https://doi.org/10.6092/ issn.2036-5195/7809

Reader, I. 2007, "Pilgrimage growth in the modern world: Meanings and implications", en Religion, 37, pp. $210-229$.

Rewilding Europe. 2016, "Making Europe a Wilder Place", en: www.rewildingeurope.com

Rigby, K. 2000, "The Politics of Pilgrimage", PAN: Philosophy Activism Nature, (1), 23.

Rotherham, I. D. 2007, "Sustaining tourism infrastructures for religious tourists and pilgrims within the UK", Religious tourism and pilgrimage festivals management: An international perspective, pp. 64-77.

Senesi, R. 2017, "Monteriggioni and the Heart of the Francigena. The Reasons Behind a Tuscan Record", Almatourism - Journal of Tourism, Culture and Territorial Development, 8(6), pp. 182-187. doi:https://doi. org/10.6092/issn.2036-5195/6667

Smith, A., \& Stirling, A. 2010, "The politics of social-ecological resilience and sustainable socio-technical transitions", Ecology and Society, N 15 (1).

Stiglitz, J. E. et al. 2009, "Report by the Commission on the Measurement of Economic Performance and Social Progress", en: http://graphics8.nytimes.com/packages/pdf/business/Stiglitzreport.pdf

Timothy, D. J., Boyd, S. W. 2003, Heritage Tourism, Harlow, Prentice Hall.

Trono, A. et al. 2017, “The Via Francigena Salentina as an Opportunity for Experiential Tourism and a Territorial Enhancement Tool", Almatourism - Journal of Tourism, Culture and Territorial Development, $\mathrm{N}^{\circ} 8(6)$, pp. 20-41. doi:https://doi.org/10.6092/issn.2036-5195/6330 
Tanaka, T. 2014, "Relation at Green Pilgrimage Network meeting", 1st-5th June 2014, en: www.ubraintv.com/ watch.php?id=56

UNESCO. 1992, "Cultural Landscapes", en: http://whc.unesco.org/en/culturallandscape

1971, "MAB, Intergovernmental Scientific Programme", en: www.unesco.org/new/en/natural-sciences/ environment/ecological-sciences/man-and-biosphere-programme/

UNWTO 2016, "Global Report on Cultural Routes and Itineraries", en: http://cf.cdn.unwto.org/sites/all/files/pdf/ global_report_cultural_routes_itineraries_v13.compressed_0.pdf

2007, Guida degli indicatori di sviluppo sostenibile per le destinazioni turistiche, Madrid.

UNESCO PRI-SM 2010, "Properties of Religious Interest - Sustainable Management", en: http://whc.unesco. org/en/religious-sacred-heritage/\#prism

Vandergeest, P. 1988, "Commercialization and commoditiza-tion: a dialogue between perspectives", Sociologia Ruralis, N 28 (1), pp. 7-29.

Vaticano 1982, "Europeistic Act in Santiago de Compostela", en: http://w2.vatican.va/content/john-paul-ii/it/ speeches/1982/november/documents/hf_jp-ii_spe_19821109_atto-europeistico.html

Von Bertalanffy, L. 1972, General System Theory: Foundations, Development, Applications, George Braziller, New York.

Wearing, S. et al. 2010, Tourist Cultures. Identity, Place and the Traveller, Sage, London. www.academia. edu/4354575/DISCOVERING_THE_VIA_FRANCIGENA

Yoshihara, H. y Inoue, N. 2018, "The Sacred Landscape of Ainu Culture and its Cultural Landscapes: Case Study on the Conservation Strategy in Biratori City, Hokkaido", Almatourism - Journal of Tourism, Culture and Territorial Development, $\mathrm{N}^{\circ} 9$ (8), pp. 107-128. doi:https://doi.org/10.6092/issn.2036-5195/7725

Yunis, E. 2009, "Religious Tourism and Sustainability", en: Dallari, F. et al. (Eds.), I viaggi dell'anima. Società, Culture, Heritage e Turism. 